\title{
É IMPOSSÍVEL COMER UM SÓ? \\ PUBLICIDADE, EMBALAGEM E CONTEÚDO DOS SALGADINHOS ELMA CHIPS
}

Is it impossible to eat only one?

Advertising, package and content of Elma Chips'snacks

\section{Es imposible tener uno?}

Publicidad, envase y contenido de aperitivos de Elma Chips

\author{
Laura Guimarães Corrêa ${ }^{1}$ \\ Tiago Barcelos Pereira Salgado ${ }^{2}$ \\ Rebeca Heringer Lisboa de Castro ${ }^{3}$
}

\section{Resumo}

Este trabalho objetiva identificar os elementos estratégicos de persuasão utilizados pela Elma Chips para conquistar consumidores potenciais, fomentando o desejo de experimentar o produto em suas diversas apresentações: embalagem, marcas, anúncios e o chips propriamente dito. Para tanto, procedemos à análise de três promoções que ofereciam tazos como brinde entre os anos de 1997 e 2002. Discutimos, ainda, questões relacionadas à regulamentação da publicidade de produtos alimentícios voltada a crianças naquela época e atualmente.

Palavras-chave: consumo, Elma Chips, indústria alimentícia, persuasão, publicidade infantil.

\begin{abstract}
This paper aims to identify some of the strategic elements that are used by Elma Chips in order to conquer its potential consumers, increasing their continuous desire to experiment the product in its various presentations: the packages, brands, commercials and the Chips itself.

\footnotetext{
${ }^{1}$ Professora do Programa de Pós-Graduação em Comunicação Social da UFMG. Coordena o núcleo de pesquisa em Publicidade, Mídia e Consumo (GrisPub) do Grupo de Pesquisa em Imagem e Sociabilidade (Gris/UFMG). E-mail: guimaraes.laura@gmail.com

${ }^{2}$ Doutorando em Comunicação Social pela UFMG. Mestre e especialista pela mesma instituição. Pesquisador associado ao núcleo de pesquisa em Publicidade, Mídia e Consumo (GrisPub) e ao Gris/UFMG. E-mail: tigubarcelos@gmail.com

${ }^{3}$ Graduada em Comunicação Social pela UFMG. Publicitária freelancer e professora de inglês na Cultura Inglesa de Belo Horizonte. E-mail: rebecaheringer@yahoo.com.br
} 
É Impossível comer um só? Publicidade, embalagem e conteúdo dos salgadinhos Elma Chips

de Laura Guimarães Corrêa, Tiago Barcelos Pereira Salgado e Rebeca Heringer Lisboa de Castro

Thus, we analyze three promotions created by Elma Chips which offered tazos as a prize in the years between 1997 and 2002. We also discuss several regulations aspects of food advertisements to children in that period and today.

Keywords: children advertising, consumption, Elma Chips, food industry, persuasion.

\section{Resumen}

Este estudio tiene como objetivo identificar los elementos estratégicos de persuasión utilizadas por Elma Chips para ganar consumidores potenciales, fomentando el deseo de probar el producto en sus diferentes presentaciones: embalaje, las marcas, los anuncios y el propio chip. Para ello, se procede al análisis de las tres promociones que ofrecen tazos como brindis entre los años 1997 y 2002. También se discuten temas relacionados con la regulación de la publicidad de los productos alimenticios destinados a los niños antes y ahora.

Palabras-clave: consumo, Elma Chips, industria alimentaria, persuasión, publicidad infantil.

\section{INTRODUÇÃO}

A empresa Elma Chips, em sua comunicação mercadológica, emprega um complexo conjunto de estratégias discursivas para a construção de imagem de marca que podem nos ajudar a compreender melhor como um universo textual e imagético foi e é apresentado às crianças, numa associação entre a alimentação e diversão. De baixo custo, os saquinhos coloridos de chips, em seus diversos formatos e sabores, têm sido um atrativo às crianças desde o seu surgimento no Brasil. Para além do universo plástico construído em volta do produto, a satisfação no ato de consumo do chips parece estar diretamente ligada à surpresa em seu interior: brindes atraentes que convidam à interação e à experimentação do produto.

Analisaremos comerciais e embalagens dos salgadinhos do período entre os anos de 1997 e 2002, buscando compreender o que fez e ainda faz os chips tão populares entre os públicos infantis. Discutimos ainda como o discurso publicitário da Elma Chips é construído de maneira a sugerir o consumo distraído e repetido dos salgadinhos entre as crianças - que se reflete na utilização do slogan "É impossível comer um só". Por fim, discutiremos questões relacionadas à regulamentação da publicidade de produtos alimentícios voltada a crianças naquela época e atualmente.

\section{ELMA CHIPS E NUTRIÇÃO}


É Impossível comer um só? Publicidade, embalagem e conteúdo dos salgadinhos Elma Chips

de Laura Guimarães Corrêa, Tiago Barcelos Pereira Salgado e Rebeca Heringer Lisboa de Castro

Fundada em 1974, a Elma Chips é uma empresa líder em salgadinhos, popularmente conhecidos como chips. A marca pertence à estadunidense Frito-Lay, que por sua vez pertence à PepsiCo, como informado nos sites dessas empresas. A marca Elma Chips tornouse rapidamente conhecida no território nacional com o slogan: "É impossível comer um só". Ao longo da década de 1990 e início dos anos 2000, era possível adquirir os chips em diversos estabelecimentos comerciais, incluindo as cantinas escolares.

Essa facilidade de compra prevaleceu até o ano de 2006, quando a venda de tais produtos em ambientes escolares passou a ser restrita a alguns estados brasileiros, por não serem considerados saudáveis. Normas, leis e manuais foram criados desde então visando à elaboração de estratégias educativas bem como a restrição da venda de produtos com altos teores de gordura saturada, gordura trans, açúcar e sal para crianças, tais como o chips.

Apesar de ainda ser possível encontrá-los em vários locais de comércio, os chips têm sido contraindicados de forma generalizada por parte de nutricionistas e guias alimentares para uma dieta saudável. De certa maneira, o sucesso de vendas dos salgadinhos pode ser facilmente explicado: baixo custo de produção/armazenamento e praticidade para os consumidores, assim como pelas estratégias persuasivas empregadas, como veremos adiante.

Os chips são alimentos com alto teor calórico, com baixos níveis de nutrientes, vitaminas e fibras, contendo aditivos alimentares prejudiciais ao organismo humano. Cook (2011) aponta que os salgadinhos de milho causam flutuação dos níveis de açúcar no sangue, levando a mudanças no humor, ganho de peso, irritabilidade, entre outros sintomas. Além disso, a maior parte desses salgadinhos é frita em óleo, o que pode desencadear processos inflamatórios. $\mathrm{O}$ sal presente nesses produtos está diretamente ligado à compulsão alimentar. Segundo David Kessler (2010), funcionário da Food and Drug Administration (FDA), os alimentos processados industrialmente têm se valido da combinação entre açúcar, gordura e sal, que estimulam os neurônios e liberam dopamina, um neurotransmissor que faz com que aumente a vontade de comer.

\section{CONSUMIR A ELMA CHIPS}

Além dos ingredientes que constituem os salgadinhos e suas possíveis consequências para o organismo humano, a marca Elma Chips é construída, ainda, por diversas outras camadas de significação que, juntas, formam sua imagem e conceito. A marca da Elma Chips 
É Impossível comer um só? Publicidade, embalagem e conteúdo dos salgadinhos Elma Chips

de Laura Guimarães Corrêa, Tiago Barcelos Pereira Salgado e Rebeca Heringer Lisboa de Castro

(Fig. 1) é constituída por um rosto infantil sorridente em branco e nas cores vermelho e preto. Segundo Perez (2004: 58), "a logo é a síntese da imagem da empresa ou de um produto. Assim, a identidade da empresa deve estar identificada, sem hesitação, na imagem da logo". A marca da Elma Chips é uma combinação de elementos gráficos, iconográficos e tipográficos que visam estimular a afeição e a receptividade à empresa e a seus produtos.

Fig. 1 - Marca Elma Chips

Fonte: Alfredojunior, 2013.

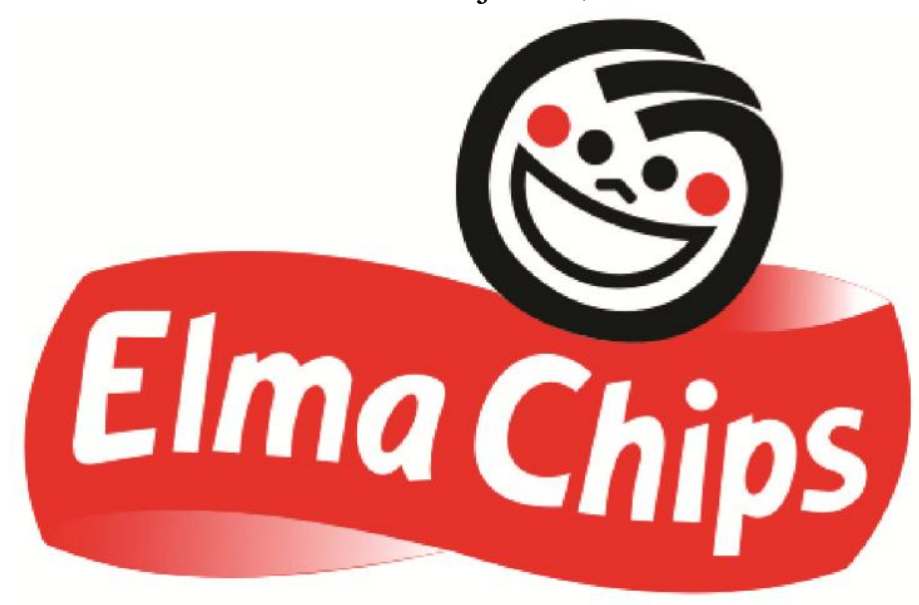

Naomi Klein (2009) aponta que as grandes marcas encontram seu sucesso principalmente no fato de que não vendem um produto propriamente dito, mas uma experiência da marca. A marca é apresentada como a força motora que permite à pessoa experimentar sensações de alegria, de prazer e descontração.

Essa experiência sugere o consumo pessoal, íntimo, ligado às emoções, a interligação entre o consumidor e a marca, que vai muito além do consumo bruto do produto. Além de ter como fim a satisfação de necessidades básicas, Barbosa (2009) também ressalta que o consumo opera na "descoberta" ou "constituição" de nossa subjetividade e identidade, ou seja, consumir significa também fazer parte de um grupo, provoca um sentimento de pertencimento.

\section{COMERCIAIS PUBLICITÁRIOS}

Ao pesquisar comerciais disponíveis no YouTube, pudemos verificar que, até aproximadamente meados da década de 1990, a Elma Chips veiculou peças que se baseavam em aspectos predominantemente físicos e químicos de seus produtos como argumentos de 
É Impossível comer um só? Publicidade, embalagem e conteúdo dos salgadinhos Elma Chips

de Laura Guimarães Corrêa, Tiago Barcelos Pereira Salgado e Rebeca Heringer Lisboa de Castro

venda. A função informativa predominava nesse tipo de comunicação, apresentando atributos como "é feito com queijo", "tem gosto de queijo", "é uma delícia”, "é feito na Queijolândia”.

Os comerciais da Elma Chips da segunda metade da década de 1990 até o início dos anos 2000 utilizam-se de argumento persuasivo mais sutil: não apresentam discurso sobre as qualidades do salgadinho, mas dos produtos em seu interior, inclusive o brinde. Há nos comerciais a sugestão de diversão, alegria, amizade, brincadeira, despertada pelas imagens das crianças brincando com os tazos, e também pelos sons, cores e personagens relacionados ao universo lúdico das crianças.

Dentre os diversos brindes lançados pela Elma Chips ao longo dos anos, os pequenos discos estampados com personagens de desenhos animados, chamados de tazos, foram destaque. Em 1997, foi lançada a campanha dos tazos "Animaniacs", seguida posteriormente pela coleção dos "Tiny Toon" (1997-1998). Os comerciais de ambas as campanhas são muito semelhantes em sua estrutura e revelam estratégias na construção do discurso persuasivo da marca. As narrativas dessas duas promoções são construídas com crianças sorrindo, parecendo se aventurar com os tazos, com o pacote do chips ao seu lado. Há utilização de personagens animados no comercial, acompanhado de uma trilha sonora de acordo com o tema, efeitos sonoros dos desenhos animados e muitas cores. Ressaltamos também que os comerciais da Elma Chips eram veiculados durante o intervalo comercial de programas infantis, tanto na TV aberta quanto na TV fechada, e os personagens de tais programas são o próprio tema dos tazos (Fig. 2). A confusão e a coincidência entre personagem e "garotopropaganda", entre intervalo e programação, também constitui a estratégia persuasiva da empresa. Assim, os limites entre apelo de consumo e entretenimento ficam borrados, favorecendo a adesão ao discurso publicitário.

Essas peças publicitárias são constituídas por significantes como: emocionante, divertido, diversão, personagens preferidos, sensacional, brincadeira, incrível e magic. Além disso, diversas ações são sugeridas, como: montar, procurar, fazer [voos incríveis] e buscar. Em nenhum momento há menção a palavras do campo semântico “comer”, "ingerir”, "alimento", nem mesmo "lanche". Os dois comerciais são igualmente concluídos com imperativos do locutor dizendo: "Vá voando buscar o seu." e, em seguida, "Ninguém consegue ficar de fora.", sugerindo o consumo como fator de inclusão e pertencimento. Importante destacar também o constante uso da palavra "salgadinho", sempre no diminutivo, que, como discutimos, pode ser uma estratégia para alcançar crianças e atenuar o fator "salgado", cheio de sal, de seu produto. 
É Impossível comer um só? Publicidade, embalagem e conteúdo dos salgadinhos Elma Chips

de Laura Guimarães Corrêa, Tiago Barcelos Pereira Salgado e Rebeca Heringer Lisboa de Castro

Fig. 2 - Comercial Tazos "Tiny Toon” - Brasil - 1998 Fonte: YOUTUBE, 2013e.

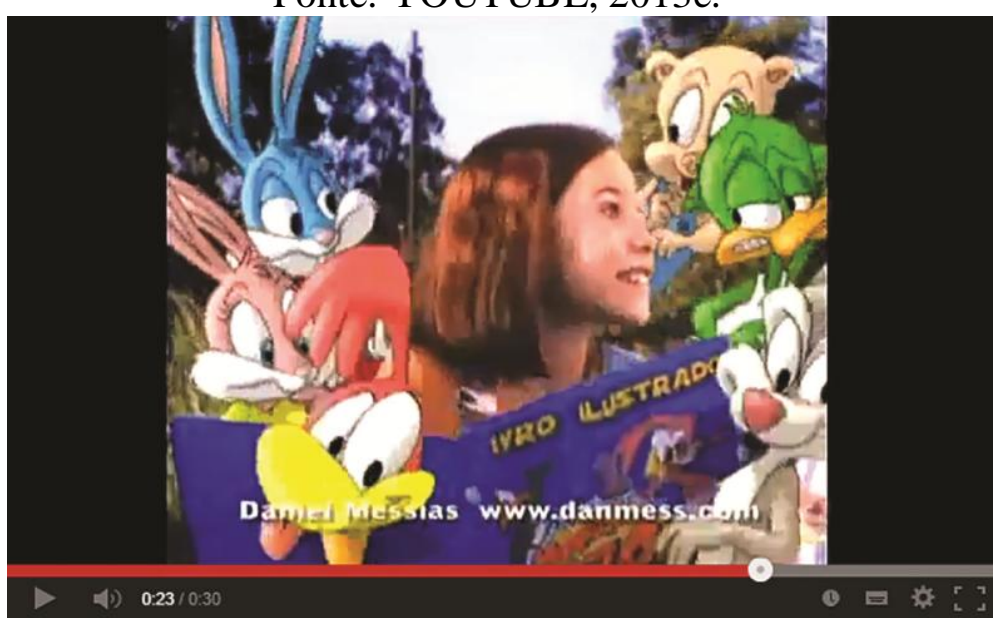

Assim como são mostradas interações da criança com o tazo, podemos perceber também como o consumo do chips é sugerido no anúncio publicitário. Uma cena presente no comercial dos tazos dos “Animaniacs” revela duas crianças quase abraçando seus pacotes de chips, ingerindo o produto, mas nem sequer estão olhando para o pacote. A atenção está voltada para os tazos e os personagens voando pelo cenário (Fig. 3). Os salgadinhos são apresentados nos comerciais como parte integrante e inofensiva da diversão, marcando sua presença de forma dinâmica, não exigindo um ritual com foco na alimentação: o assentar-se à mesa em uma cadeira, com pratos e talheres, possivelmente com outras pessoas e prestando atenção ao alimento. As crianças comem distraidamente, sem perceber o que fazem.

Fig. 3 - Comercial Tazos “Animaniacs” - Brasil - 1997

Fonte: YOUTUBE, 2013d.

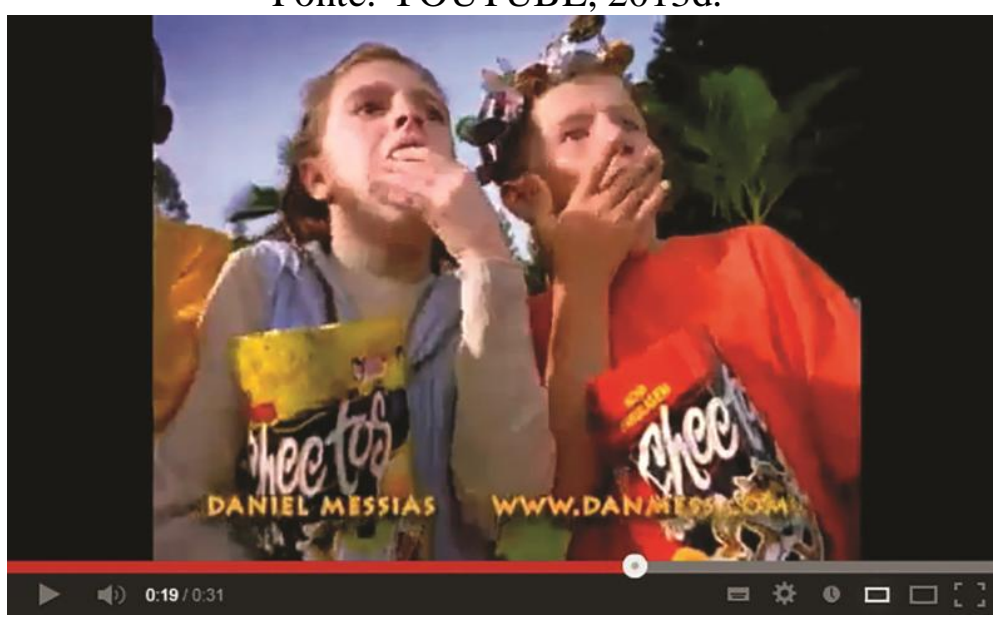


É Impossível comer um só? Publicidade, embalagem e conteúdo dos salgadinhos Elma Chips

de Laura Guimarães Corrêa, Tiago Barcelos Pereira Salgado e Rebeca Heringer Lisboa de Castro

Em 2002, a Elma Chips promoveu a campanha "Toon Tazo na Copa", na qual os tazos tinham como tema o futebol, os jogadores e jargões presentes nesse esporte. Em um dos anúncios veiculados naquele ano, o produto propriamente dito só aparece em destaque nos segundos finais do comercial. Ao longo de todo o anúncio apenas os tazos ganham menção, enquanto o salgadinho aparece apenas de maneira sutil, quase invisível, sufocado no meio das crianças brincando com os brindes (YOUTUBE, 2013g).

Além disso, não se trata apenas de ter um tazo: a quantidade é importante, pois é com vários deles que se torna possível "disputar emocionantes partidas de tazo". Podemos perceber, então, uma sugestão ao colecionismo, que permitirá a troca, as brincadeiras, e a incessante busca pelos tazos especiais (prata, dourado, de metal, "gigatazo", ouro), ou seja, um apelo ao consumo constante do chips.

Há um desvio da atenção e da ênfase do produto principal para o brinde, que aqui representa a brincadeira, o jogo por trás, ou por dentro do chips. Assim, os comerciais vendem mais a experiência de ter o tazo do que a de comer o próprio chips. A aquisição do produto é o pressuposto para o jogo. Comprado o brinquedo, o salgadinho é ingerido, como um complemento da brincadeira.

\section{EMBALAGENS}

Os produtos preparados industrialmente são armazenados em embalagens que lhes proporcionem longa permanência nas prateleiras dos estabelecimentos comerciais. No caso dos salgadinhos Elma Chips, o produto é embalado em pacote de material metalizado e flexível, protegendo-o da umidade. No entanto, muito mais do que uma proteção ao produto, as embalagens são o principal contato entre o produto propriamente dito e quem o consome.

Segundo Perez (2004), a embalagem cumpre cinco funções fundamentais: a diferenciação, a atração, o efeito espelho (no é estabelecida uma correspondência entre o produto e a auto-imagem do consumidor), a sedução e a informação. Vimos anteriormente que, até o início dos anos 1990, a publicidade dos salgadinhos apresentava caráter informativo. Percebemos que o mesmo acontecia nas embalagens até então, com seu aspecto e design simples, sem personagens famosos de desenhos infantis estampados, com a presença rara de brindes, conferindo maior destaque à imagem do chips propriamente dito no centro da embalagem. 
É Impossível comer um só? Publicidade, embalagem e conteúdo dos salgadinhos Elma Chips

de Laura Guimarães Corrêa, Tiago Barcelos Pereira Salgado e Rebeca Heringer Lisboa de Castro

Diante do crescimento e da competitividade do mercado, a diferenciação se tornou, então, necessária. Podemos notar que os anúncios publicitários e as embalagens, especialmente a partir de meados da década de 1990, têm tentado levar às crianças a ideia de que seu produto é o mais gostoso, e são os próprios personagens animados que falam isso a elas, personagens a que elas estão acostumadas, que elas sentem que entendem, amam e com os quais se sentem confortáveis, diz Michael Rich, médico do Children's Hospital Boston, no documentário Consuming Kids (BARBARO; EARP 2008). Rich observa também que, quando essas marcas se apropriam, com o intuito de obter lucro, de um personagem que diz às crianças "coma tal coisa", estão na verdade se apropriando de profundas e poderosas emoções e conexões que a criança tem com o personagem. Ao longo da história dos salgadinhos e suas coleções de brindes, notamos que sua divulgação é feita em diferentes partes da embalagem, mas sempre lhe conferindo maior destaque nas prateleiras. Durante a década de 1990 e início dos anos 2000, estavam presentes nas embalagens dos chips os personagens animados tema das promoções, além dos mascotes da Elma Chips: o guepardo e o espantalho.

De acordo com Perez (2004: 94), “a palavra mascote remete à figura de pessoas, animais ou coisas consideradas capazes de trazer ou proporcionar sorte e felicidade.”. Em complementação, a autora aponta que, no plano organizacional, o objetivo principal da utilização do mascote é o de humanizar a marca, ou seja, realizar a personificação da empresa.

Há algumas características em comum nos mascotes das mais diversas marcas, e em especial aqueles da indústria alimentícia. Primeiramente, os mascotes são na maioria das vezes mamíferos e outros seres antropomorfizados. Tal fato pode estar relacionado à ideia de cuidado e carinho sugeridos por essa classe de animais, além de serem também animais fortes, ativos e aventureiros, e que são desse modo associados a heróis.

Além dos personagens das promoções e mascotes da Elma Chips, a escolha das cores das embalagens constitui elemento persuasivo. Os salgadinhos da Elma Chips mantêm, ao longo da história da marca, um padrão de cores em suas embalagens, embora haja algumas inovações ocasionalmente. Os primeiros chips e que permanecem no mercado até hoje, como Doritos, Fandangos, Cheetos, Ruffles, entre outros, vêm sempre em embalagem de cores quentes ${ }^{4}$ como o vermelho, o amarelo, o laranja. Existem apenas dois modelos azuis, Cheetos

\footnotetext{
4 “As cores tem temperatura, não uma temperatura física, mas uma sensação associativa intermediada pelos códigos da linguagem. [...] A percepção de temperatura agrega-se à questão dinâmica de aproximação e afastamento." (PEREZ, 2004: 80).
} 
É Impossível comer um só? Publicidade, embalagem e conteúdo dos salgadinhos Elma Chips

de Laura Guimarães Corrêa, Tiago Barcelos Pereira Salgado e Rebeca Heringer Lisboa de Castro

sabor Requeijão e Ruffles. A escolha das cores não se dá de maneira aleatória. Como apresentado por Guimarães (2004), o vermelho é uma cor quente e intensa, incitando-nos emoções fortes e a vontade de comer. O amarelo, por outro lado, é comumente utilizado para despertar a atenção, alegria e aquecimento. A cor laranja é percebida, segundo estudos sobre a psicologia das cores, como ligada à criatividade, alegria, entusiasmo, diversão e juventude. O azul, por sua vez, estaria relacionado a sentimentos de calma, dignidade, estabilidade e confiabilidade. O vermelho, o amarelo e o laranja são frequentemente utilizados em embalagens de alimentos por serem cores que influenciam o apetite.

A tipografia utilizada pela Elma Chips em suas embalagens constitui também parte da estratégia persuasiva. Além do contorno e da ideia de movimento nelas presente, as fontes são impressas em negrito e em itálico no caso do Doritos, dando destaque ainda maior para o nome e, no caso deste último, intensificando a sensação de energia e agitação.

Revela-se então uma estratégia de vendas da indústria alimentícia destinada às crianças que associa diretamente a alimentação à brincadeira. Com a Elma Chips isso se deu especialmente por meio dos tazos que, especialmente no período em questão, resultaram em uma associação entre uma necessidade biológica (alimentação) e um desejo infantil (o brinquedo), os quais nunca são plenamente satisfeitos.

\section{BRINCAR E COMER}

As marcas produtoras de junk food (porcarias), frequentemente, promovem brindes, surpresas, brinquedos que acompanham seus produtos nas prateleiras, atraindo a atenção das crianças e fazendo confundir a fome com a vontade de brincar. A criança muitas vezes deseja o alimento pelo brinde, desejo associado também aos demais fatores estratégicos que constroem a imagem da marca, como o sabor, a embalagem, as cores e os personagens. Dessa maneira, os brindes não apenas promovem e estimulam esse tipo de alimento como também ofuscam a compreensão da criança sobre o quê e por que comer.

A primeira coleção de tazos lançada pela Elma Chips no Brasil foi dos Looney Tunes (Fig. 4), em 1997. Juntamente com os tazos, diversos acessórios e tazos especiais foram desenvolvidos para acompanhar as brincadeiras, caracterizando o colecionismo sugerido e almejado pela marca, que impulsionaria e prolongaria o consumo do chips. 
É Impossível comer um só? Publicidade, embalagem e conteúdo dos salgadinhos Elma Chips

de Laura Guimarães Corrêa, Tiago Barcelos Pereira Salgado e Rebeca Heringer Lisboa de Castro

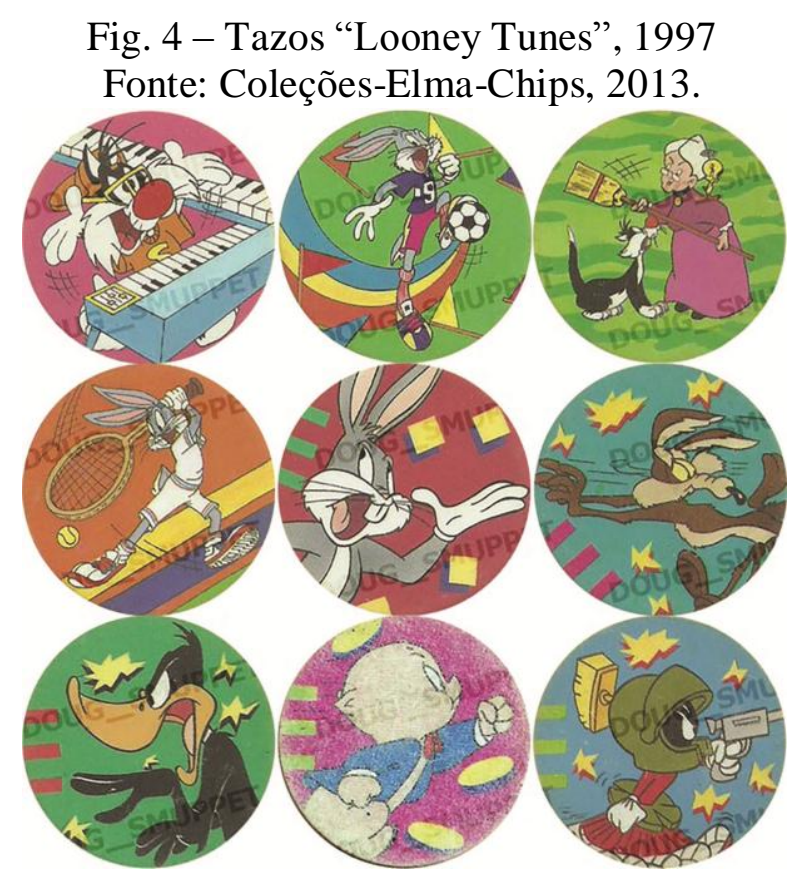

Mantello (2012: 2), apropriando-se da teoria lacaniana, diz que "o desejo humano não está diretamente implicado numa relação pura e simples com o objeto que o satisfaz, mas à sua posição na presença desse objeto e fora de sua relação com ele, de maneira que jamais se esgota”. Desse modo, compreendemos que a Elma Chips aproveitou a necessidade infantil de brincar e a associou ao consumo do chips e de seus brindes, utilizando personagens familiares a eles: mascotes, embalagens, palavras, sons e cores, que juntos cooperaram para o intenso (em quantidade) e extenso (em tempo) consumo de seus salgadinhos.

\section{COMER REPETIDA E COMPULSIVAMENTE}

Uma outra estratégia que podemos perceber ser utilizada pela marca de maneira a direcionar o consumidor para a ingestão impulsiva de seu produto é a sugestão de consumo, a começar pelo tamanho da embalagem. Os salgadinhos do tipo chips não são vendidos em pequenas embalagens, não contêm apenas algumas unidades do produto. Muito pelo contrário, o consumo integral é implícito na embalagem, apesar da "porção" indicada na tabela nutricional não dizer o mesmo. Contudo, uma vez em contato com o oxigênio do ar, o chips começa a perder a sua qualidade crocante, logo seu consumo provavelmente não se dará em mais de um momento.

As crianças, os personagens e a locução em off dos comerciais em momento algum dizem "coma quando estiver com fome", ou "coma com moderação". Pelo contrário, apenas 
É Impossível comer um só? Publicidade, embalagem e conteúdo dos salgadinhos Elma Chips

de Laura Guimarães Corrêa, Tiago Barcelos Pereira Salgado e Rebeca Heringer Lisboa de Castro

trazem sentenças imperativas como "coma", "compre", "vá correndo comprar", dissociadas da fome. Cada propriedade e característica dos salgadinhos é planejada de maneira a promover o maior prazer no consumidor.

A Frito-Lay foi ao longo de sua história responsável por diversas pesquisas, que chegaram a custar cerca de 30 milhões de dólares por ano, visando desenvolver a qualidade crocante ideal para seus salgadinhos, além de garantir que seus produtos estejam sempre frescos nas prateleiras (MOSS, 2013). O ato de abrir um pacote de chips, então, sugere o consumo integral do produto e leva ao desejo por mais do sabor salgadinho, neste pacote e no próximo, o que reflete a escolha do slogan da Elma Chips: "É impossível comer um só.".

\section{8. ÉTICA E LEGISLAÇÃO NA PUBLICIDADE INFANTIL}

Segundo dados do Ministério da Saúde de 2010, o sobrepeso atinge cerca de $33 \%$ das crianças entre 5 e 9 anos no Brasil. De acordo com o documentário "Muito além do peso" (BORGES, 2012), crianças com sobrepeso aumentam o consumo de junk food em $134 \%$ quando expostas à sua publicidade.

O período entre os anos de 1997 e 2002 foi marcado pela intensa presença da Elma Chips entre as crianças brasileiras, a começar pelos comerciais na televisão. Além disso, a promoção de tazos anunciada nos comerciais e nas embalagens eram elementos que atraíam ainda mais a atenção das crianças, que tinham fácil acesso aos salgadinhos.

As diversas estratégias persuasivas utilizadas pela Elma Chips para atrair seus públicos - sendo os infantis os principais, mas não exclusivos - parecem ter sido, de fato, efetivas ao longo da década de 1990 e começo dos anos 2000. Todavia, a preocupação despertada por parte de médicos e nutricionistas, assim como a publicização de informações sobre os efeitos desse tipo de alimentação, permitiu que esse quadro fosse gradualmente se alterando por meio de disputas e embates envolvendo profissionais da saúde e ONGs como o Instituto Alana, anunciantes, veículos e entidades de classe como a Associação Brasileira de Agências de Publicidade (ABAP) e Conselho Nacional de Autorregulamentação Publicitária (Conar).

Atualmente, o Governo brasileiro tem buscado implementar normas mais rígidas à publicidade infantil, mas ainda é permissivo se comparado com outros países onde o assunto encontra-se em discussão há mais tempo. Para a pesquisadora Inês Vitorino, o Brasil precisa ter uma "regulamentação que defina limites à intervenção publicitária", pois "atualmente 
É Impossível comer um só? Publicidade, embalagem e conteúdo dos salgadinhos Elma Chips

de Laura Guimarães Corrêa, Tiago Barcelos Pereira Salgado e Rebeca Heringer Lisboa de Castro

quem mais atua nessa área é o Conar, mas, por se tratar de um órgão privado de autorregulamentação, seu código não tem força de lei e ele não tem poder para garantir punições mais severas" (Band Notícias, 2012). Além disso, o Conar é uma entidade que congrega atores envolvidos diretamente com o mercado publicitário, como agências, veículos e anunciantes e, portanto, apresenta visão interessada sobre os temas polêmicos em discussão.

O Código Brasileiro de Autorregulamentação Publicitária, de junho de 2013, "condena a ação de merchandising ou publicidade indireta contratada que empregue crianças, elementos do universo infantil ou outros artifícios com a deliberada finalidade de captar a atenção desse público específico, qualquer que seja o veículo utilizado" (Art. 37). ${ }^{5}$ Ainda nesse artigo lê-se que esse tipo de anúncio deve "abster-se de encorajar ou relevar o consumo excessivo, nem apresentar situações que incentivem o consumo exagerado ou conflitem com esta recomendação". Além disso, o Código desaprova o uso de imperativos como "compre" ou "peça para seus pais".

Os comerciais da Elma Chips por nós analisados claramente conflitariam com a legislação atual. Contudo, não podemos atribuir à publicidade veiculada na televisão toda a responsabilidade pelo consumo de alimentos não saudáveis. A publicidade não está apenas nos intervalos comerciais, mas está também dentro dos programas infantis, estampada nos materiais escolares das crianças, nos supermercados, nos filmes, na web, entre outros meios.

Além das proibições mencionadas, o Governo Federal e diversos estados brasileiros vêm estabelecendo campanhas, regulamentações e resoluções para a indústria alimentícia infantil. No entanto, os chips continuam sendo vendidos com seus ingredientes danosos ao organismo humano, e contendo a recompensa pelo consumo em seu interior: os brindes.

Em março de 2014, o Conselho Nacional dos Direitos da Criança e do Adolescente (Conanda), publicou a Resolução no. 163 no Diário Oficial da União, que considera abusivo o direcionamento de publicidade e de comunicação mercadológica à criança, "com a intenção de persuadi-la para o consumo de qualquer produto ou serviço". No entanto, essa recomendação tem sido ignorada. Os anúncios voltados para crianças continuam nos jornais, nos comerciais de televisão, nos sites e nas embalagens.

A relação entre publicidade infantil da indústria alimentícia e obesidade tem sido tema de diversos estudos ao redor do mundo, os quais comprovam a influência e as consequências

\footnotetext{
${ }^{5}$ Disponível em: <http://www.conar.org.br/>. Acesso em: 17 out. 2013.
} 
É Impossível comer um só? Publicidade, embalagem e conteúdo dos salgadinhos Elma Chips

de Laura Guimarães Corrêa, Tiago Barcelos Pereira Salgado e Rebeca Heringer Lisboa de Castro

dessa exposição. Entretanto, não se deve considerar que a comunicação publicitária se dê de acordo com uma lógica funcional e determinista de estímulo-resposta. A recepção dos discursos persuasivos acontece de forma mais complexa do que a simples transmissão de mensagens, ainda que voltadas ao público infantil. A responsabilidade pela obesidade infantil ou pelos maus hábitos alimentares não deve ser exclusivamente atribuída à publicidade, mas também à sociedade (com seus hábitos e costumes) na qual ela se insere.

\section{CONSIDERAÇÕES FINAIS}

Diante do que foi exposto, percebemos que a experiência, os atributos e sensações anunciadas pela Elma Chips operam de maneira a fomentar o desejo dos potenciais consumidores, que nunca é plenamente satisfeito. Essa experiência, contudo, pode ter consequências opostas ao clima construído em torno do produto, pois, mesmo associado à brincadeira, trata-se de alimento prejudicial à saúde, potencialmente cancerígeno e escasso em nutrientes.

Como observamos no material analisado, crianças e adolescentes foram interpelados ao longo da década de 1990 por promessas de alegria, diversão, aventura e prestígio na publicidade e no conteúdo dos chips. Localizamos também uma valorização da quantidade de salgadinho ingerido. Os comerciais da Elma Chips, assim como as embalagens, mascotes, cores, vendem um produto a ser consumido repetida e inevitavelmente, pois: "É impossível comer um só.”.

Comer "um só" pode ser mesmo uma tarefa difícil, uma vez que o produto está ao alcance visual das crianças em muitos lugares, inclusive na grade de programação televisiva. Pode também parecer impossível comer um só pelo fato de o produto propiciar fortes estímulos às papilas gustativas, além de oferecer brindes de recompensa ao consumo, como os tazos, estampando personagens que ativam a afeição e atenção de crianças e adolescentes.

A publicidade alimentícia (e seus elementos persuasivos analisados aqui), a grande oferta de alimentos industrializados a preços baixos, a praticidade em comparação aos alimentos frescos que demandam preparo são alguns dos outros fatores que têm distanciado as crianças da alimentação e hábitos saudáveis. O sedentarismo e a falta de informação clara e correta nas embalagens podem também ser vistos como algumas das causas da obesidade infantil no Brasil e no restante do mundo hoje. Outras doenças causadas pela má alimentação 
É Impossível comer um só? Publicidade, embalagem e conteúdo dos salgadinhos Elma Chips

de Laura Guimarães Corrêa, Tiago Barcelos Pereira Salgado e Rebeca Heringer Lisboa de Castro

têm preocupado médicos e nutricionistas, como os problemas cardíacos, diabetes, câncer, colesterol alto, entre outros.

A publicidade voltada a crianças é elemento fundamental de agenciamento do desejo de consumo, porém, sua regulamentação, por si só, é insuficiente. É importante que os alimentos e seus componentes sejam fiscalizados e que sejam realizadas ações do poder público para promoção da saúde em favor de uma sociedade que se alimente conscientemente, a começar pelas crianças. Acreditamos que cabe aos pais e mães, mas não só a essas pessoas, a responsabilidade de "impor limites para a relação da criança com o consumo e a mídia" (PIEDRAS, 2013: 150).

Os embates discursivos e as disputas legais sobre a regulamentação ou mesmo a proibição de ações mercadológicas relacionadas à promoção dos salgadinhos processados e outros alimentos prejudiciais à saúde continuam em curso no Brasil. Podem ser notadas, nas práticas e peças publicitárias contemporâneas, transformações em relação àquelas no período em que analisamos. Entretanto, trata-se de território complexo, em que diversos interesses econômicos estão em jogo. Interesses antagônicos e disputas desiguais seguem definindo, de forma permissiva, os limites da comunicação publicitária nos dias de hoje.

\section{REFERÊNCIAS BIBLIOGRÁFICAS}

ANVISA. Disponível em: <http://portal.anvisa.gov.br>. Acesso em: 16 ago. 2013.

BARBARO, A. EARP, J. Consuming Kids. EUA, 2008. Vídeo (66 min), color.

BANDNOTICIAS. Brasil precisa regular publicidade infantil. Disponível em: <http://noticias.band.uol.com.br/brasil/noticia/?id=100000507720>. Acesso em: 29 out. 2013.

BARBOSA, Lívia. Cultura, Consumo e Identidade. Rio de Janeiro: FGV, 2009.

BOCOCK, Roberto. Consumption. London: Routledge, 1993.

BORGES, Juliana. Muito além do peso. Vídeo (84 min), color. 2012.

COOK, Michelle. 10 Worst Foods of All Time. Disponível em: $<$ http://www.borkenhagen.net/imagens/scanner/10worstfoods.pdf $>$. Acesso em: 17 ago. 2013.

DIÁRIO OFICIAL DA UNIÃO. Resolução n. 163, de 13 de março de 2014. Disponível em: $<$ http://pesquisa.in.gov.br/imprensa/jsp/visualiza/index.jsp?jornal=1\&pagina=4\&data= 04/04/2014>. Acesso em: 03 ago. 2014. 
É Impossível comer um só? Publicidade, embalagem e conteúdo dos salgadinhos Elma Chips

de Laura Guimarães Corrêa, Tiago Barcelos Pereira Salgado e Rebeca Heringer Lisboa de Castro

GUIMARÃES, Luciano. A cor como informação. São Paulo: Annablume, 2004.

KESSLER, David. Açúcar, sal e gordura viciam e fazem o corpo querer cada vez mais comida. $O$ Globo online, 16 mar. $2010 . \quad$ Disponível em: $<$ http://oglobo.globo.com/saude/acucar-sal-gordura-viciam-fazem-corpo-querer-cadavez-mais-comida-3039449>. Acesso em: 05 set. 2013.

KLEIN, Naomi. SEM LOGO. Rio de Janeiro: Record, 2009.

MANTELlO, Paulo. Motivação para o consumo: desejo e suas implicações na contemporaneidade. 2012. Disponível em: <http://bocc.ubi.pt/pag/mantello-paulomotivacao-para-consumo-desejo-implicacoes.pdf>. Acesso em: 02 nov. 2013.

MINISTÉRIO DA SAÚDE. Obesidade cresce mais entre crianças na faixa de 5 a 9 anos. Disponível em: <http://www.brasil.gov.br/saude/2012/01/obesidade-cresce-maisentre-criancas-na-faixa-de-5-a-9-anos>. Acesso em: 03 ago. 2014.

MOSS, Michael. Salt, Sugar, Fat. How the food giants hooked us. UK: WH Allen, 2013.

PEREZ, Clotilde. Signos da Marca: expressividade e sensorialidade. São Paulo: Thomson, 2004.

PIEDRAS, Elisa. Vulnerabilidade ou resistência? Um panorama da questão do consumo infantil de alimentos permeado pelo marketing e a mídia. Comunicação, Mídia e Consumo, São Paulo, v. 10, n. 29: 143-159, set./dez. 2013. Disponível em: $<$ http://revistacmc.espm.br/index.php/revistacmc/article/view/304/pdf $>$. Acesso em: 03 ago. 2014.

YOUTUBE. Vídeo Comercial Antigo Cheetos da Elma Chips (1990). 2013a. Disponível em: <http://www.youtube.com/watch?v=8kRON3rqxUk>. Acesso em: 02 jul. 2013.

YOUTUBE. Vídeo Comercial Cheetos da Elma Chips, 1991. 2013c. Disponível em: <httap://www.youtube.com/watch?v=50oKUFTrAmg>. Acesso em: 02 jul. 2013.

YOUTUBE. Vídeo Comercial Elma Chips - Tazos Animaniacs. 2013d. Disponível em: <http://www.youtube.com/watch?v=83T1M9Dv_sA>. Acesso em: 02 jul. 2013.

YOUTUBE. Vídeo Comercial Elma Chips - Tazos Tiny Toon. 2013e. Disponível em: <http://www.youtube.com/watch?v=mCuo6xDEzLo>. Acesso em: 02 jul. 2013.

Artigo submetido: 15/06/2014

Artigo aprovado: 29/06/2014 